\title{
Taming Hypervalent Bonds and Strained Rings for Catalysis and Synthesis
}

\author{
Florian de Nanteuil, Yifan Li, Maria Victoria Vita, Reto Frei, Eloisa Serrano, Sophie Racine, and \\ Jérôme Waser ${ }^{\S}$
}

§Werner Prize 2014

\begin{abstract}
Improving the synthesis of complex organic molecules is essential for progress in many fields such as medicine, agrochemicals or materials. Since 2007, our laboratory has been focusing on the development of non-classical bond disconnections based on the use of small, energy-loaded organic molecules: hypervalent iodine reagents and strained rings. In this overview article, we report our progress since 2011 in these areas. The use of cyclic hypervalent iodine reagents has been extended to the C2-selective alkynylation of indoles, the domino cyclization alkynylation of allenes, the alkynylation of thiols and the azidation of carbonyl compounds. Amino-substituted aminocyclopropanes and aminocyclobutanes were used in [3+2] and [4+2] annulations to access nitrogen-rich building blocks, including nucleoside analogues. The first example of dynamic kinetic [3+2] annulation of aminocyclopropanes with both enol ethers and aldehydes was also reported.
\end{abstract}

Keywords: Acetylenes · Activated cyclopropanes · Catalysis · Hypervalent iodine $\cdot$ Synthesis

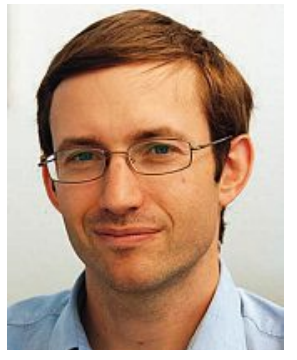

Jérôme Waser was born in Sierre, Valais, Switzerland in 1977. He obtained his chemistry diploma from ETH Zurich in 2001. In 2006, he completed his $\mathrm{PhD}$ studies at ETH Zurich with Prof. Erick M. Carreira. He then joined Prof. Barry M. Trost at Stanford University as a postdoctoral fellow. From October 2007 to May 2014, he worked as assistant professor at EPF Lausanne, focusing on the development of synthetic methods. In June 2014, he was promoted to associate professor at EPFL. He is a recipient of the A. F. Schläfli award of the Swiss Academy of Sciences 2011, the ERC starting grant 2013 and the Werner Prize 2014 of the Swiss Chemical Society.

${ }^{\star}$ Correspondence: Prof. Dr. J. Waser

Ecole Polytechnique Fédérale de Lausanne Laboratory of Catalysis and Organic Synthesis EPFL SB ISIC LCSO $\mathrm{BCH} 4306$

$\mathrm{CH}-1015$ Lausanne

Tel.: +41216939388

E-mail: jerome.waser@epfl.ch

\section{Introduction}

Improving the synthesis of complex organic molecules is essential for progress in many fields such as medicine, agrochemicals or materials. Whereas improving known processes and making them more efficient and environmental friendly is certainly an important field of research, developing new disconnections of chemical bonds is more challenging, but can also be highly rewarding. Indeed, new reactions often allow several steps to be cut in a synthetic sequence, accelerating the discovery of new molecules and making complete domains of the chemical space easily accessible. Since 2007, our laboratory has been focusing on the development of non-classical bond disconnections based on the use of small, energy-loaded organic molecules: hypervalent iodine reagents and strained rings (Scheme 1). The energy gain obtained by breaking weak hypervalent bonds to make stronger ones or by strain-release through ring-opening of small rings allows access to non-conventional synthons with a reversal of the reactivity normally induced by functional groups (Umpolung in its broader sense). In a previous overview article in CHIMIA, we presented our pioneering work on the use of cyclic ethynyl benziodoxolone (EBX) reagents for the Umpolung of alkynes and the discovery of the first catalytic formal homo-Nazarov reaction. ${ }^{11]}$ Concerning the former, we first introduced the alkynylation of ketoesters, ${ }^{[2]}$ electron-rich aromatic compounds ${ }^{[3]}$ and olefins. ${ }^{[4]}$ For the latter, we made use of cross-polarized vinyl-cyclopropyl ketones to access cyclohexenones under mild conditions. ${ }^{[5]} \mathrm{We}$ then introduced the use of aminocyclopropanes in this process for the synthesis of indole alkaloids. ${ }^{[6]}$ Herein, we would like to present our more recent work in these two areas. In particular, we will show how we could access differently alkynylated heterocycles based either on a change of catalyst or on domino cyclization-alkynylation processes. ${ }^{[7]} \mathrm{We}$ will then describe the alkynylation of thiols, ${ }^{[8]}$ as well as the extension of the use of cyclic hypervalent iodine reagents to the azidation of carbonyl compounds. ${ }^{[9]}$ In the field of strained rings, more convergent methods based on annulation reactions of aminocyclopropanes ${ }^{[10]}$ and -cyclobutanes ${ }^{[11]}$ will be presented, resulting in the efficient synthesis of cyclobutyl-, cyclopentyl-, tetrahydrofuryl- and cyclohexylamines.

\section{Cyclic Hypervalent lodine Reagents}

In our earlier work, we demonstrated that the alkynylation of heterocycles was possible with TIPS-EBX (1a) under mild conditions using a gold catalyst. ${ }^{[3]}$ The reaction proceeded with high regioselectivity for the more electron-rich position of indoles, pyrroles, thiophenes and anilines. Although the high regioselectivity was useful, it also constituted a major challenge if access to heterocycles alkynylated at other positions was desired. In the case of indoles, we were able to switch 


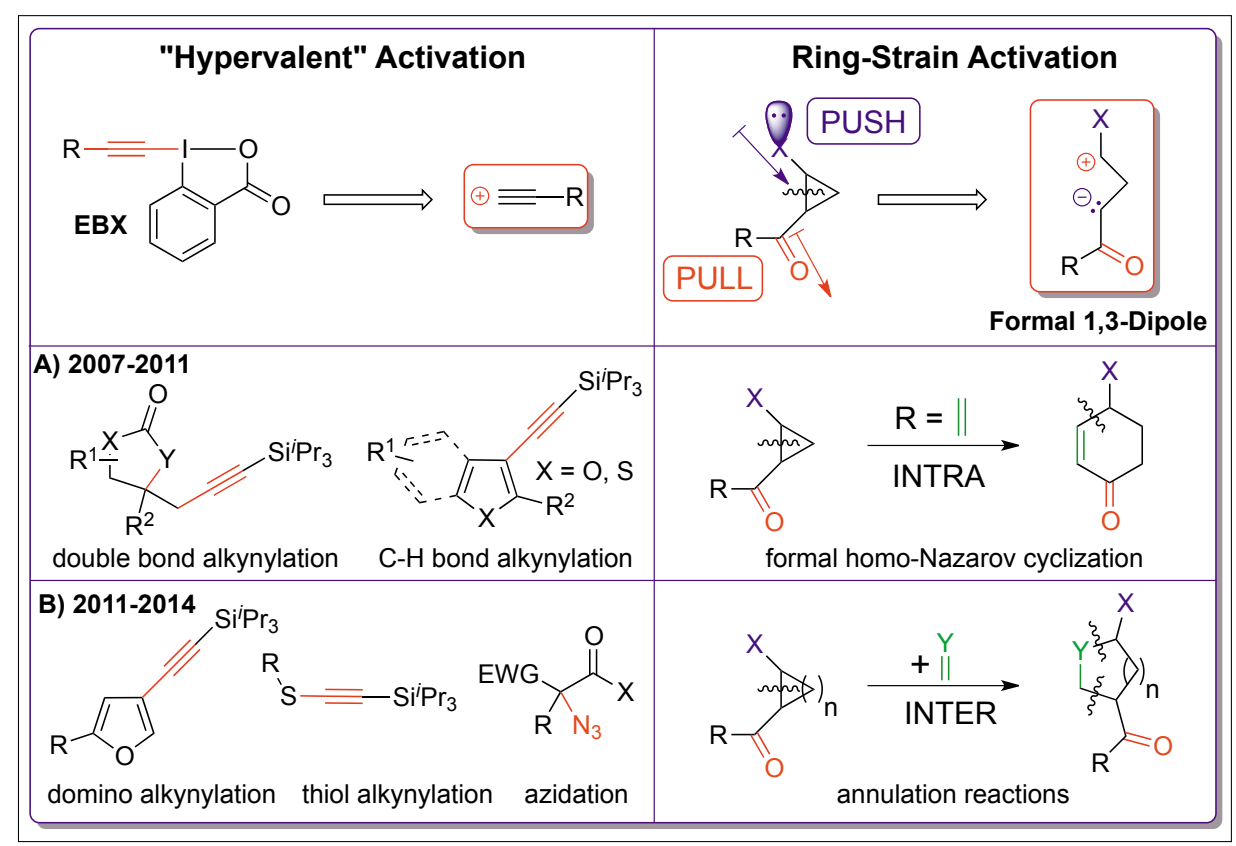

Scheme 1. Development of new reactions in our laboratory based on the activation of hypervalent bonds and weak rings.

the regioselectivity from $\mathrm{C} 3$ to $\mathrm{C} 2$ just by changing the catalyst from gold to palladium (Scheme 2, products 3a-3c). ${ }^{[7 a]}$ The selectivity may be due to the higher stability of the intermediate with the palladium in the $\mathrm{C} 2$ position. Nevertheless, this approach was applicable only for indoles for which the electron-rich position is not adjacent to the heteroatom. In the case of furans for example, the gold-catalyzed process also gave $\mathrm{C} 2$-alkynylation. In principle, if a C3-metallated furan could be accessed, alkynylation at this position would become possible. Instead of using a $\mathrm{C}-\mathrm{H}$ functionalization method, we wondered if such an intermediate could be accessed via a cyclization reaction of allenes developed by Hashmi and co-workers. ${ }^{[12]}$ The main challenge in this approach was that organometallic gold intermediates are notoriously difficult to intercept, except with proton or iodine. We originally hypothesized that a gold(I) catalyst would be ideally suited to promote the desired domino cyclization-alkynylation process, but none of the tested catalysts was successful. In contrast, we found out that gold(III) picolinic acid complex 5 was uniquely successful for this process together with modified hypervalent iodine reagent $\mathbf{1 b}$ (Scheme 3). ${ }^{[7 b]}$ This points out a further advantage of cyclic hypervalent iodine reagents: the easy modulation of their electronic properties through modification of the group in trans position to the alkyne. The domino process was successful for a broad range of aryl and alkyl substituted allenes (prod-

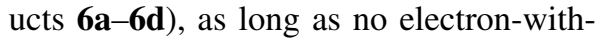
drawing substituent was present on the allene: in this case, solvent addition on the allene or polymerization dominated. This work demonstrated that domino-processes are indeed valuable to access alkynylated heterocycles difficult to synthesize via a $\mathrm{C}-\mathrm{H}$ functionalization approach. Further investigations are ongoing in our laboratory to extend this strategy to the synthesis of other alkynylated aromatic compounds.

Up to 2013, we had focused on the alkynylation of $\mathrm{C}$-nucleophiles. We wondered if the reaction could also be successful in the case of heteroatoms. Heteroatomsubstituted alkynes are very interesting building blocks due to their exceptional reactivity, but they are usually difficult to access. In the case of ynamides however, the development of new synthetic methods has led to their widespread use in organic chemistry. ${ }^{[13]}$ We were especially interested in the alkynylation of sulfur, as the obtained thioalkynes could find broad application not only in synthetic chemistry, but also in chemical biology and materials science. Nevertheless, this class of compounds is usually accessed using multistep procedures under relatively harsh conditions. One of the major issues when

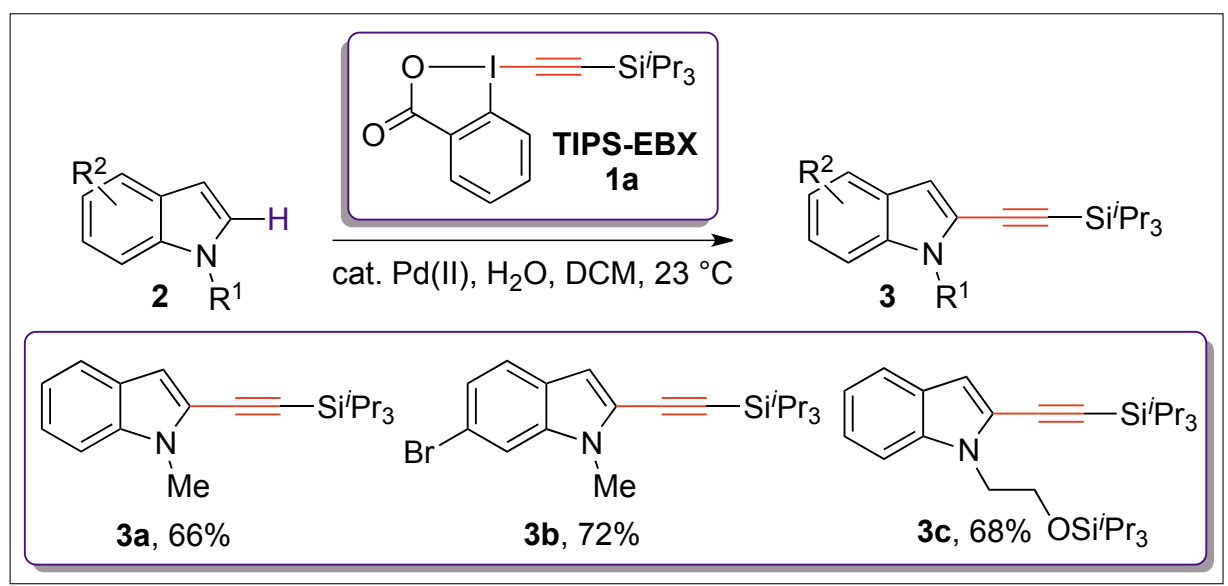

Scheme 2. Pd-catalyzed C2-alkynylation of indoles.

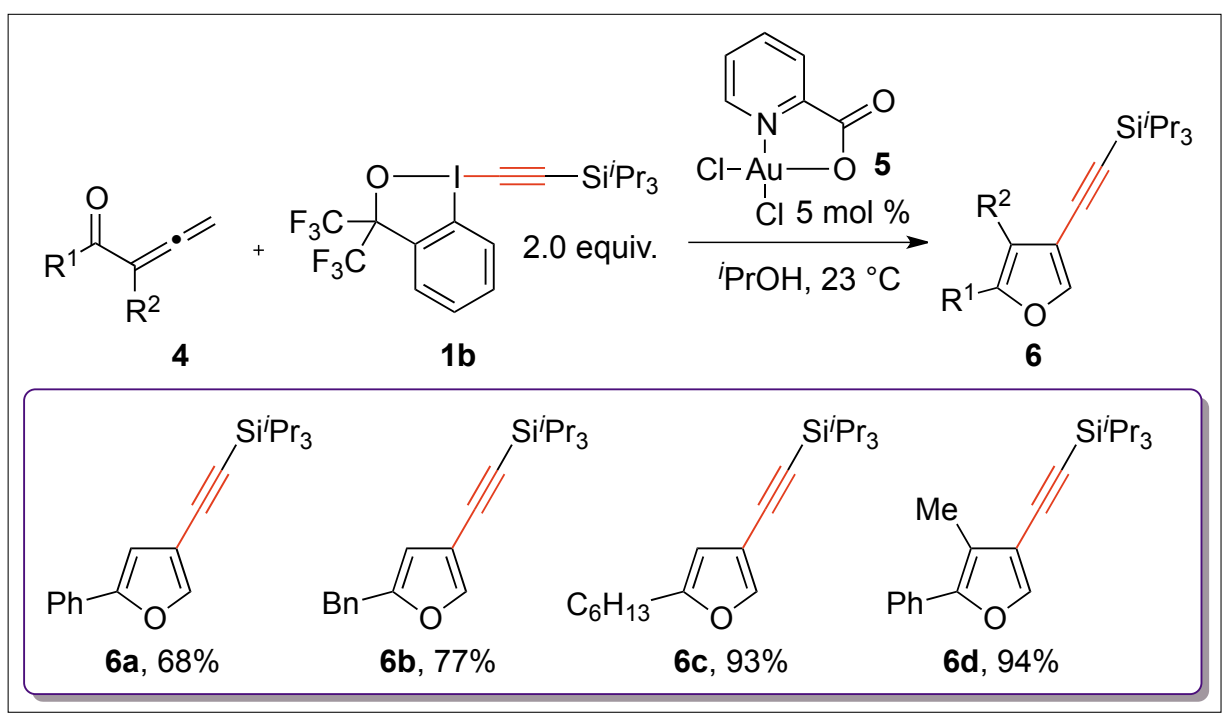

Scheme 3. Gold-catalyzed domino cyclization-alkynylation of allenes. 
developing the alkynylation of thiols was to suppress the competing disulfide formation, which is especially facile with oxidation reagents. We were pleased to see that the unique combination of TIPS-EBX (1a) and tetramethylguanidine (TMG) as a base led to quantitative alkynylation of a broad range of aliphatic and aromatic thiols (Scheme 4, products $8 \mathbf{8}-\mathbf{g}$ ). ${ }^{[8]}$ The reaction was tolerant to a broad range of functional groups and could also be applied to heteroaromatic thiols (products $\mathbf{8 h}-\mathbf{i}), \quad$ N-unprotected cysteine ester $\mathbf{7 j}$ (product $\mathbf{8 j}$ ) and peptides (products $\mathbf{8 k}, \mathbf{l}$ ). The most impressive feature of this reaction is its efficiency: complete conversion to the alkynylation product was observed in less than one minute! On a dipeptide, it used exclusively for the functionalization of radicals. ${ }^{[16]}$ We first found that dimethylbenziodoxole 1c was indeed able to azidate cyclic ketoesters without the addition of any catalyst in nearly quantitative yield (Scheme 5, product 11a).[9] Nevertheless, the reaction was not successful in the case of less reactive acyclic ketoesters or silyl enol ethers. The use of zinc triflate as catalyst finally allowed the azidation of these two classes of substrates under mild conditions (products 11b and 12a,b). When we were working on this transformation, Gade and co-workers also reported that azidobenziodoxole 1c could be used for the enantioselective azidation of cyclic ketoesters using a chiral iron catalyst.[17]
To summarize this part of our research program, we have further extended the versatility of ethynylbenziodoxole reagents to diverse alkynylation processes. The use of other catalysts or domino processes allowed us to access alkynylated heterocycles which could not be synthesized easily before. The first efficient process was developed for thiol alkynylation. Different research groups have also shown that EBX reagents could be used in other $\mathrm{C}-\mathrm{H}$ functionalization processes ${ }^{[18]}$ or the alkynylation of carbonyl compounds, ${ }^{[19]}$ tosyl amides, ${ }^{[20]}$ and radicals. ${ }^{[21]}$ Finally, our preliminary results obtained for azidation further confirm that the use of benziodoxolone reagents in organic chemistry has just started to be investigated, and many more

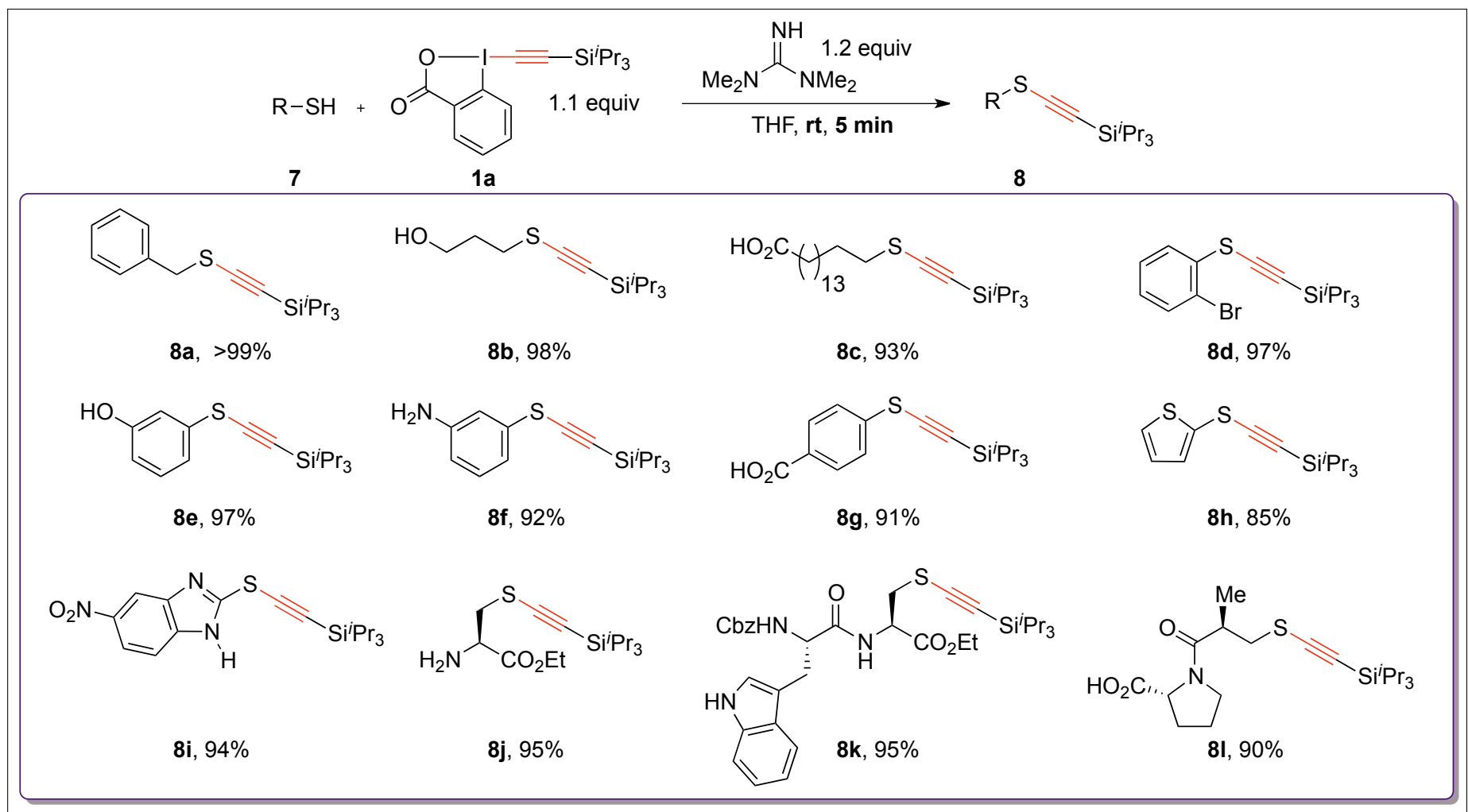

Scheme 4. Alkynylation of thiols.

was also possible to deprotect the alkyne and perform a cycloaddition with an azide to introduce a fluorophore. Current work in our laboratory focuses on applying the method to the alkynylation of thiols in biomolecules.

Both our work on alkynylation and the work of Togni's group on trifluoromethylation ${ }^{[14]}$ had demonstrated that benziodoxole reagents have exceptional properties for atom-transfer reactions. ${ }^{[15]}$ We wondered consequently if the concept could be extended to the introduction of other functional groups. In this context, we became particularly interested in azidobenziodoxole reagents, which were introduced by Zhdankin and co-workers and have been

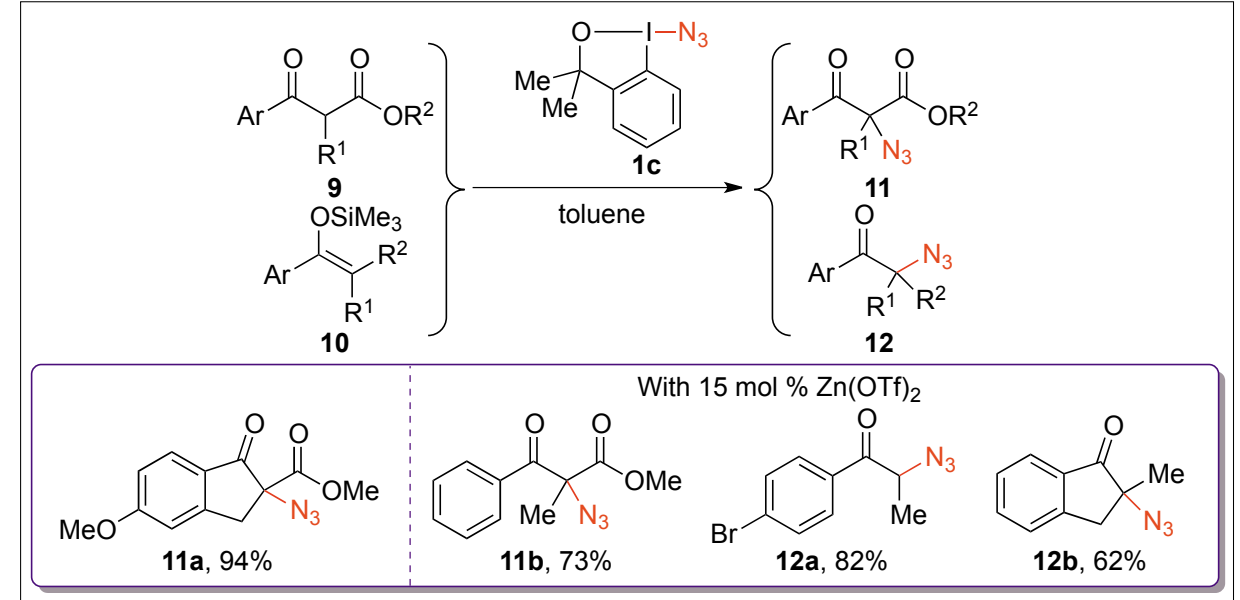

Scheme 5. Azidation of carbonyl compounds. 
fascinating transformations still wait to be discovered.

\section{Annulation Reactions of Aminocyclopropanes and Aminocyclobutanes}

During our early work, we had discovered the exceptional properties of aminocyclopropanes in cyclization reactions, in particular the formal homo-Nazarov process, and we applied them in the synthesis of indole alkaloids. ${ }^{6]}$ Although the strategy developed was highly successful, the synthesis of the vinylketone aminocyclopropanes was challenging and required several steps, which made it less attractive. We wondered consequently if more convergent methods based on annulation processes in which several bonds would be formed in a single transformation could be developed. In fact, [3+2] annulation reactions of donor-acceptor cyclopropanes have been studied extensively in the past, ${ }^{[22]}$ yet no example of aminocyclopropane was known in this process. This was highly surprising when considering the preponderance of cyclopentyl- and tetrahydrofurylamines in synthetic and natural bioactive compounds. On the other hand, the high nucleophilicity of nitrogen makes the synthesis and manipulation of donor-acceptor aminocyclopropanes especially challenging. In 2011, we achieved a breakthrough in this area by introducing phthalimido-substituted diester cyclopropanes (Scheme 6). ${ }^{[10 a]}$ Using a tin catalyst, the $[3+2]$ annulation with enol ethers proceeded in high yield and diastereoselectivities to give cyclopentylamines $\mathbf{1 5 a}-\mathbf{d}$. Later, we were also able to extend the reaction to aldehydes (products $\mathbf{1 5 e , f})^{[10 b]}$ and ketones (products $\mathbf{1 5 g}, \mathbf{h})^{[10 \mathrm{c}]}$ as partners using, respectively, iron trichloride and tin tetrachloride, as catalysts. The tin-catalyzed processes occurred at low temperature and were stereospecific, giving access to enantioenriched products. Nevertheless, the synthesis of the required enantiopure aminocyclopropanes could not be achieved and the enantiomers were separated on a chiral column. This was naturally unsatisfactory, and we wondered if a dynamic kinetic asymmetric transformation (DYKAT) could be developed, in which racemic aminocyclopropanes would be transformed into enantiopure cyclopentylamines. ${ }^{[23]}$ Such processes are challenging, as both interconversion of the enantiomers and facial selectivity need to be controlled. We finally reached this goal using copper catalyst 17 bearing a commercially available bisoxazoline (BOX) ligand (Scheme 7). ${ }^{[10 d]}$ To obtain high enantioselectivities, it was essential to replace the phthalimido group by a succinimide. Interestingly, the

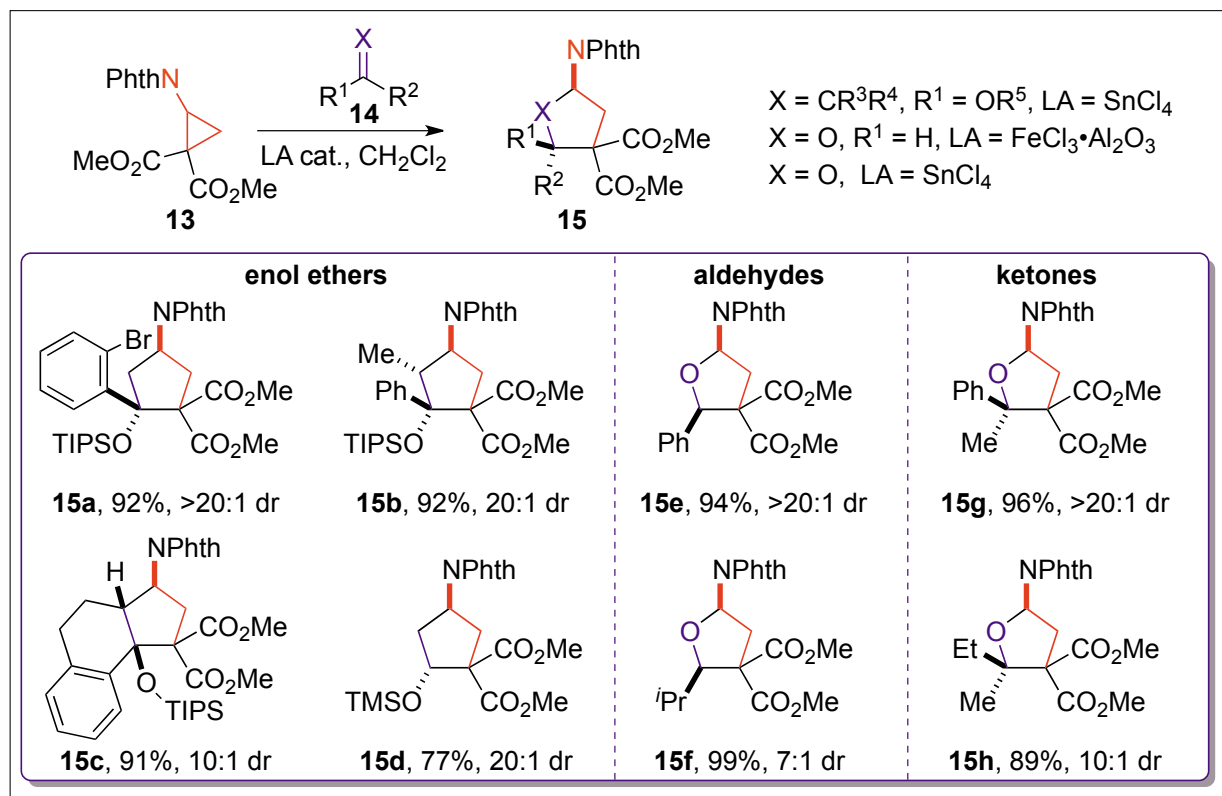

Scheme 6. [3+2] Annulation of aminocyclopropanes with enol ethers, aldehydes and ketones.

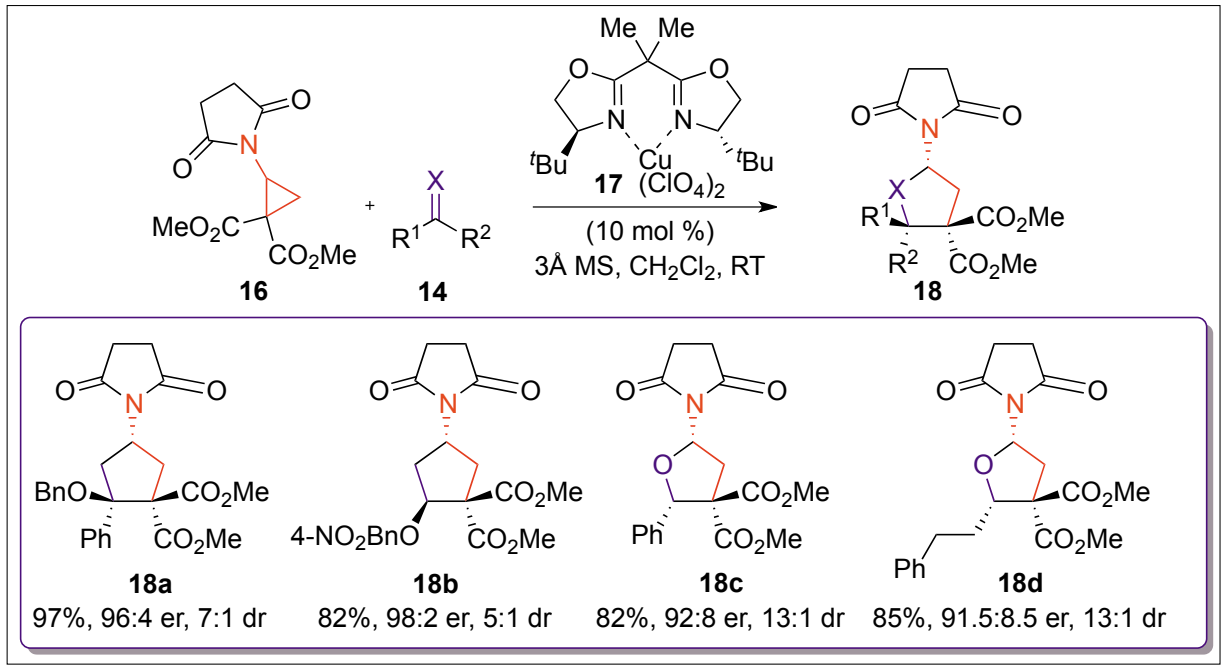

Scheme 7. Dynamic kinetic asymmetric [3+2] annulation.

$[3+2]$ annulation proceeded in high enantioselectivities not only with enol ethers (products 18a,b), but also for the reaction with aldehydes (products 18c,d).

One of the obvious applications for the cyclopentyl- and tetrahydrofurylamines obtained in the annulation process is the synthesis of nucleoside analogues. With more than 45 FDA approved drugs, this class of compounds is indeed most important for medicinal chemistry. In principle, the nucleobase could be elaborated on the nitrogen group using known procedures after phthalimide deprotection. ${ }^{[24]}$ Nevertheless, the resulting synthetic sequence would be relatively long. Furthermore, deprotection of the more sensitive tetrahydrofurylamines could not be achieved so far. We consequently wondered if the nucleobases themselves could be used as donor groups on the cyclopropane. Comparison of the pKa values for phthalimide (9.9) and thymine (8.3) indi- cated that the two groups may have similar electronic properties. We were indeed able to develop a synthesis of thymine, uracil and fluoro-uracil substituted diester cyclopropanes and were pleased to see that they were good partners in the $[3+2]$ annulation with enol ethers, ketones and aldehydes (products 20a-e, Scheme 8). ${ }^{[10 \mathrm{e}]}$

So far, we had demonstrated the excellent reactivity of phthalimido diester cyclopropanes in [3+2] annulation reactions. We then wondered if the same reactivity could be observed for the potentially less reactive aminocyclobutanes. The synthesis of the required donor-acceptor substituted cyclobutanes had never been reported before and represented an important goal in itself. In 2013, we discovered that iron chloride on alumina was an excellent catalyst for the reaction of enimides with alkylidene malonates (products $\mathbf{2 3 a}-\mathbf{h}$, Scheme 9A). ${ }^{[11]}$ The reaction tolerated substituents on both partners and could be scaled up 


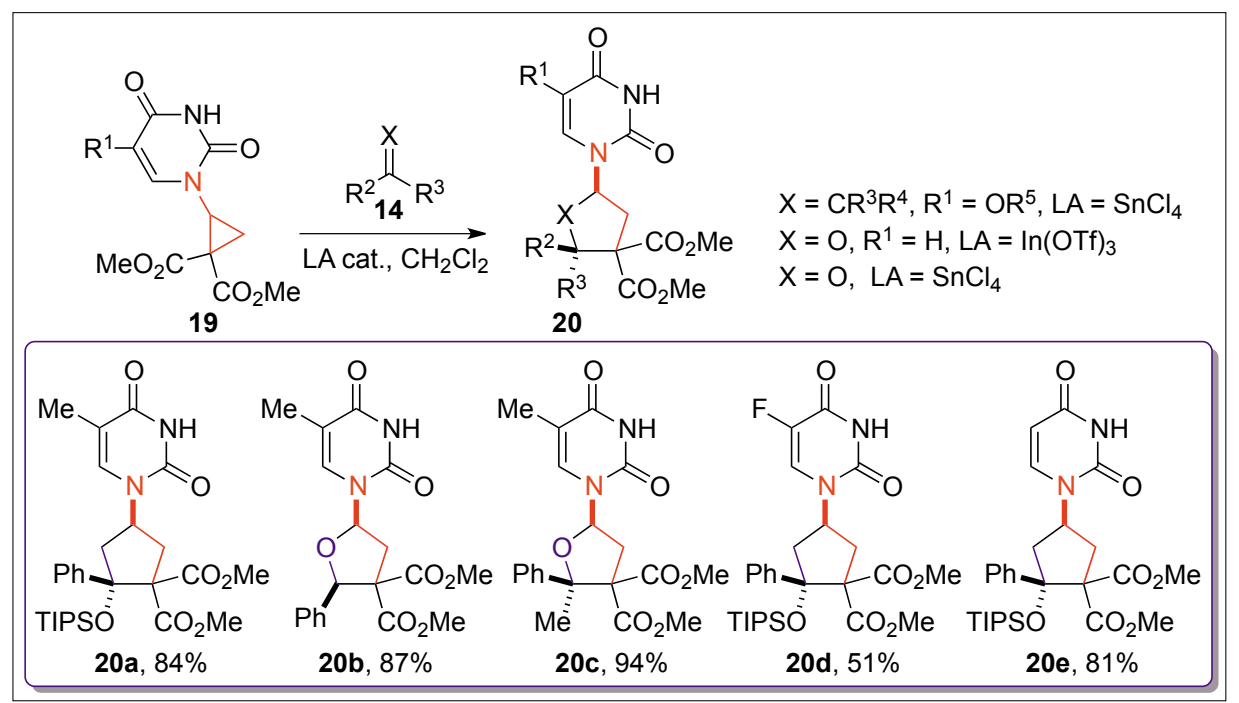

Scheme 8. Synthesis of nucleoside analogues via [3+2] annulation.

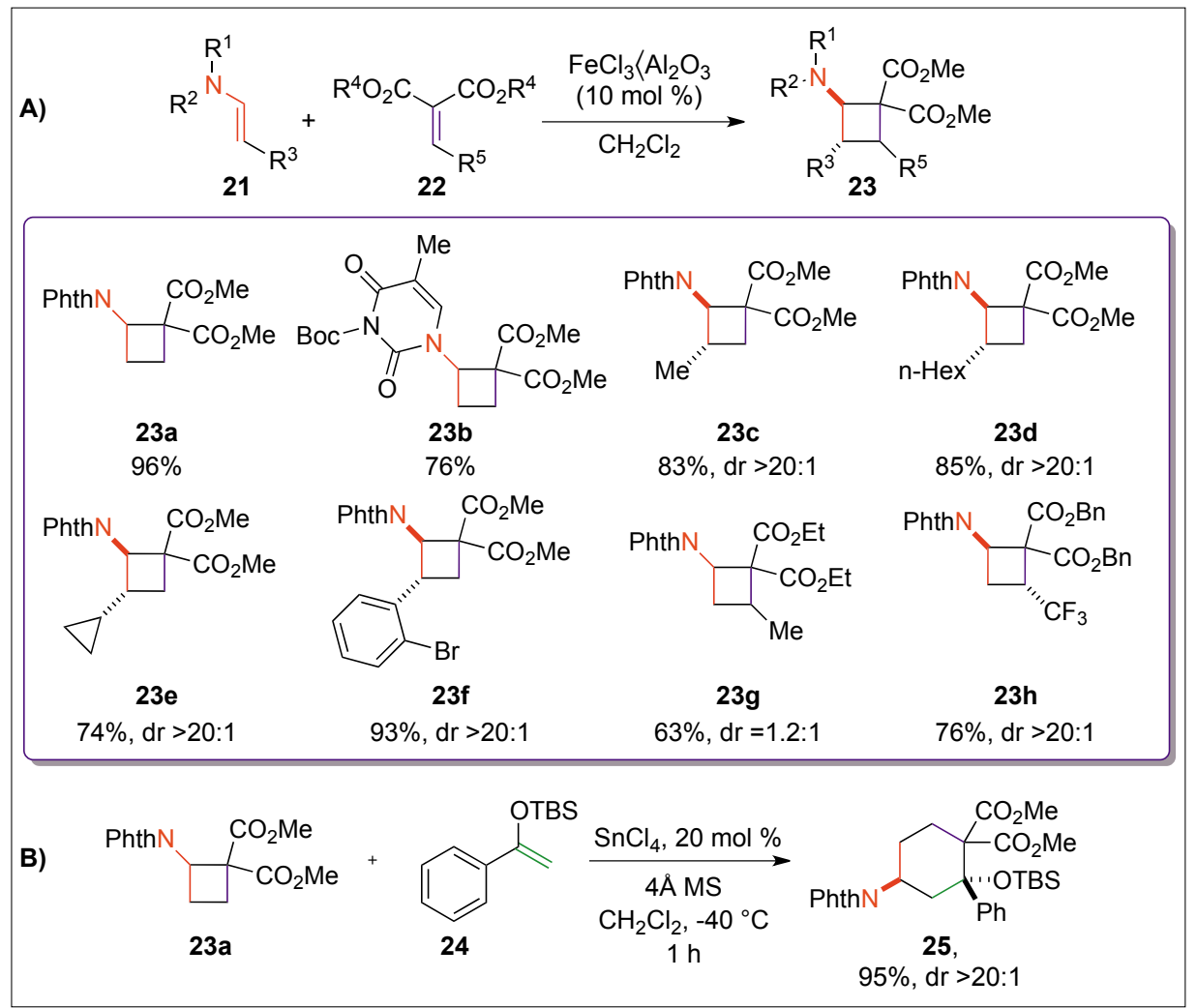

Scheme 9. Synthesis of aminocyclobutanes via [2+2] cycloaddition (A) and [4+2] annulation of aminocyclobutane 23a with enol ether 24 (B).

to the multi-gram scale. Finally, the first example of [4+2] annulation between aminocyclobutane 23a and enol ether $\mathbf{2 4}$ was realized (Scheme 9B). This preliminary result is highly promising for the development of further annulation processes.

To conclude this part, we have discovered that the combination of an imido donor group with a diester acceptor group led to a new type of donor-acceptor substituted small rings, which is uniquely successful in [3+2] and [4+2] reactions. These unique properties have been also recently used by other groups in $[8+3]$ annulation reactions of tropones. ${ }^{[25]}$ Many more inter- of cyclic hypervalent iodine reagents was also successful for azidation. In the case of small ring chemistry, we have developed more convergent annulation methods to access important building blocks. We are convinced we have only just started to explore the potentials of weak hypervalent bonds and strain rings in synthetic chemistry, and many new transformations still remain to be discovered.

\section{Received: June 24, 2014}

[1] a) D. Fernandez Gonzalez, F. De Simone, J. P. Brand, S. Nicolai, J. Waser, Chimia 2011, 65, 649. Reviews on hypervalent iodine: b) V. V. Zhdankin, P. J. Stang, Tetrahedron 1998, 54, 10927 ; c) V. V. Zhdankin, P. J. Stang, Chem. Rev. 2008, 108, 5299. First reports on ethynyl benziodoxoles: d) M. Ochiai, Y. Masaki, M. Shiro, J. Org. Chem. 1991, 56, 551; e) V. V. Zhdankin, C. J. Kuehl, A. P. Krasutsky, J. T. Bolz, A. J. Simonsen, J. Org. Chem. 1996, 61, 654.

[2] D. Fernández González, J. P. Brand, J. Waser, Chem. Eur. J. 2010, 16, 9457.

[3] a) J. P. Brand, J. Charpentier, J. Waser, Angew. Chem., Int. Ed. 2009, 48, 9346; b) J. P. Brand, J. Waser, Angew. Chem., Int. Ed. 2010, 49, 7304; c) J. P. Brand, J. Waser, Org. Lett. 2012, 14 , 744; d) J. P. Brand, C. Chevalley, R. Scopelliti, J. Waser, Chem. Eur. J. 2012, 18, 5655

[4] a) S. Nicolai, S. Erard, D. Fernández González, J. Waser, Org. Lett., 2010, 12, 384; b) S. Nicolai, C. Piemontesi, J. Waser, Angew. Chem., Int. Ed. 2011, 50, 4680.

[5] F. De Simone, J. Andres, R. Torosantucci, J. Waser, Org. Lett. 2009, 11, 1023.

[6] a) F. De Simone, J. Gertsch, J. Waser, Angew. Chem., Int. Ed. 2010, 49, 5767; b) F. De Simone, T. Saget, F. Benfatti, S. Almeida, J. Waser, Chem. Eur. J. 2011, 17, 14527; c) R. Frei, D. Staedler, A. Raja, R. Franke, F. Sasse, S. Gerber-Lemaire, J. Waser, Angew. Chem., Int. Ed. 2013, 52, 13373.

[7] a) G. L. Tolnai, S. Ganss, J. P. Brand, J. Waser, Org. Lett. 2013, 15, 112; b) Y. Li, J. P. Brand, J. Waser, Angew. Chem., Int. Ed. 2013, 52, 674.

[8] R. Frei, J. Waser, J. Am. Chem. Soc. 2013, 135, 9620.

[9] M. V. Vita, J. Waser, Org. Lett. 2013, 15, 3246.

[10] a) F. de Nanteuil, J. Waser, Angew. Chem., Int. Ed. 2011, 50, 12075; b) F. Benfatti, F. de Nanteuil, J. Waser, Org. Lett. 2012, 14, 386; c) F. Benfatti, F. de Nanteuil, J. Waser, Chem. Eur. J. 2012, 18, 4844; d) F. de Nanteuil, E. Serrano, D. Perrotta, J. Waser, J. Am. Chem. Soc. 2014, 136, 6239; e) S. Racine, F. de Nanteuil, E. Serrano, J. Waser, Angew. Chem., Int. Ed. 2014, 53, DOI: 10.1002/anie.201404832R1.

[11] F. de Nanteuil, J. Waser, Angew. Chem., Int. Ed. 2013, 52, 9009.

[12] A. S. K. Hashmi, L. Schwarz, J. H. Choi, T. M. Frost, Angew. Chem., Int. Ed. 2000, 39, 228.

[13] G. Evano, A. Coste, K. Jouvin, Angew. Chem., Int. Ed. 2010, 49, 2840.

[14] a) I. Kieltsch, P. Eisenberger, A. Togni, Angew. Chem., Int. Ed. 2007, 46, 754; b) R. Koller, K. Stanek, D. Stolz, R. Aardoom, K. Niedermann, A. Togni, Angew. Chem., Int. Ed. 2009, 48 , 4332.

Since our last report in CHIMIA in 2011, we have progressed in our research on hypervalent iodine reagents and small rings to access non-conventional synthons. New catalyst systems and domino processes have led to alternative methods to access alkynylated heterocycles. A very efficient and practical method for the alkynylation of thiols has been developed and the use
[15] J. P. Brand, D. Fernández González, S. Nicolai, J. Waser, Chem. Commun. 2011, 47, 102.

[16] a) V. V. Zhdankin, C. J. Kuehl, A. P. Krasutsky, M. S. Formaneck, J. T. Bolz, Tetrahedron Krasutsky, C. J. Kuehl, A. J. Simonsen, J. K. Woodward, B. Mismash, J. T. Bolz, J. Am. Chem. Soc. 1996, 118, 5192. Lett. 1994, 35, 9677; b) V. V. Zhdankin, A. P 
[17] Q. H. Deng, T. Bleith, H. Wadepohl, L. H. Gade, J. Am. Chem. Soc. 2013, 135, 5356.

[18] a) Y. Ohta, Y. Tokimizu, S. Oishi, N. Fujii, H. Ohno, Org. Lett. 2010, 12, 3963; b) F. Xie, Z Qi, S. Yu, X. Li, J. Am. Chem. Soc. 2014, 136, 4780; c) A. Nierth, M. A. Marletta, Angew. Chem., Int. Ed. 2014, 53, 2611; d) C. Feng, T.-P Loh, Angew. Chem., Int. Ed. 2014, 53, 2722; e) K. D. Collins, F. Lied, F. Glorius, Chem. Comm. 2014, 50, 4459 .

[19] a) H. Shi, L. Fang, C. Tan, L. Shi, W. Zhang, C. C. Li, T. Luo, Z. Yang, J. Am. Chem. Soc. 2011, 133, 14944; b) M. Kamlar, P. Putaj, J. Veselý, Tetrahedron Lett. 2013, 54, 2097; c) Z. Wang, X. Li, Y. Huang, Angew. Chem., Int. Ed. 2013, 52, 14219; d) L. F. Silva Jr, A. Utaka, L. Calvalcanti, Chem. Comm. 2014, 50, 3810.

[20] T. Aubineau, J. Cossy, Chem. Comm. 2013, 49 , 3303.

[21] a) X. Liu, Z. Wang, X. Cheng, C. Li, J. Am. Chem. Soc. 2012, 134, 14330; b) H. Huang, G. Zhang, L. Gong, S. Zhang, Y. Chen, J. Am. Chem. Soc. 2014, 136, 2280

[22] Selected reviews: a) H. U. Reissig, R. Zimmer, Chem. Rev. 2003, 103, 1151; b) F. De Simone, J Waser, Synthesis 2009, 3353; c) T. F. Schneider, J. Kaschel, D. B. Werz, Angew. Chem., Int. Ed. 2014, 53, 5504.

[23] Selected examples of DYKAT using arylsubstituted diester cyclopropanes: a) A. T. Parsons, J. S. Johnson, J. Am. Chem. Soc. 2009 131, 3122; b) H. Xu, J. P. Qu, S. H. Liao, H Xiong, Y. Tang, Angew. Chem., Int. Ed. 2013. $52,4004$.

[24] G. Shaw, R. N. Warrener, M. H. Maguire, R. K. Ralph, J. Chem. Soc. 1958, 2294.

[25] a) R. Tejero, A. Ponce, J. Adrio, J. C. Carretero, Chem. Comm. 2013, 49, 10406; b) A. R. Rivero, I. Fernandez, M. A. Sierra, Org. Lett. 2013, 15, 4928. 